\title{
Klinik Olarak Anlamlı Karotis Arter Stenozlarının Değerlendirilmesinde Renkli Doppler Görüntüleme, Manyetik Rezonans Anjiyografi ve Dijital Subtraksiyon Anjiyografi Yöntemlerinin Karșılaștırılması
}

\author{
Comparison of Color Doppler Ultrasound Imaging and Magnetic Resonance Angiography with Digital Subtraction \\ Angiography in Clinically Significant Carotid Artery Stenosis
}

\author{
Ebru Düșünceli Atman1', Evren Üstüner'1, Çağlar Uzun1', Hasan Özcan², IIlhan Erden1, \\ Tanzer Sancak³ ${ }^{3}$ Umman Sanlıdilek
} 'Ankara Üniversitesi Tıp Fakültesi Radyoloji Anabilim Dalı, Ankara ÖZzel TOBB ETÜ Hastanesi, Radyoloji Bölümü, Ankara
Amac: Bu çalıșmada renkli Doppler ultrasonografi (RDUS) ve kontrastlı 3 boyutlu manyetik rezonans anjiyografinin (MRA) karotis arter stenozu tanısında referans inceleme yöntemi olan dijtal subtraksiyon anjiyografisi (DSA) ile karșılaștırılması ve tanısal etkinliklerinin araștırılması amaçlandı.

Gereç-Yöntem: Klinik ve laboratuar bulguları ile karotis arter stenozu ön tanısı olan, yașları 33-80 arasında değișen (ortalama 55.85), $15^{\prime} \mathrm{i}$ erkek, $5^{\prime} \mathrm{i}$ kadın toplam 20 olgu çalıșmaya dahil edildi. Her olguda ana, eksternal ve internal karotis arterler olmak üzere 6 arter segmenti incelendi. Olguların tümüne RDUS, 18 olguya DSA ve 16 olguya MRA yapıldı. Ondört olguda ise her üç inceleme de gerçekleștirildi. Stenoz derecelerine göre olgular \%0-39, \%40-59, \%6079, \%80-99 ve oklüzyon olmak üzere 5 gruba ayrıldı. Ayrıca NASCET'e göre kritik stenoz değeri olan \%70'e göre olgular, \%70 ve üzeri ile \%70'in altı olmak üzere 2 gruba ayrıldı. RDUS ve MRA sonuçları altın standart yöntem olan DSA sonuçları karssılaștııılarak her iki incelemenin karotis arter stenozunu saptamadaki duyarlıık, özgüllük ve uyumları McNemar, kappa ve Spearman's korelasyon testleri ile belirlendi.

Bulgular: Çeșitli stenoz derecelerinde RDUS'nin duyarılığı \%100, özgüllüğü \%95.3-99.1, MRA'nın duyarlılı̆ı \%100, özgüllüğğ ise \%98.6-100; oklüzyonda ise RDUS'nin duyarlıı̆ı \%100, özgüllüğü \%99.1, MRA'nın duyarlılığı \% 100, özgüllüğü \% 100 olarak saptandı. Her iki inceleme ile DSA arasında mükemmel uyum (RDUS için $\mathrm{K}=0.86-0.92, \mathrm{MRA}$ için $\mathrm{K}=0.95-1$ ) ve kuvvetli pozitif korelasyon (RDUS için $\mathrm{r}=0.92$, MRA için $\mathrm{r}=1$ ) saptandı. Kritik stenoz değeri olan $\% 70$ ve üzerine göre yapılan sınıflandırmaya göre RDUS'nin duyarlılığı \%100, özgüllüğü \%94.8 olarak bulundu. Ayrıca RDUS ile DSA arasında yüksek uyum saptandı ( $\kappa=0.80$ ). MRA'nın ise duyarııı̆ı \%100, özgüllüğü ise \%97.3 olarak bulunurken DSA ile arasındaki uyum derecesi mükemmel olarak saptandı $(\kappa=0.89)$.

Sonuç: Noninvazif, iyonize radyasyon ve arteryel kateterizasyona bağlı riskler tașımayan RDUS ve MRA, karotis arter stenozu șüphesi olan olgularda, yüksek duyarlılık ve özgüllük değerleri ile DSA'ya alternatif olarak güvenle kullanılabilir.

Anahtar Sözcükler: Karotis Stenozu, Doppler UItrasonografi, MR Anjiyografi, Kateter Anjiyografi

Aim: In this study, we aimed to compare the color Doppler ultrasonography (CDUS) and three-dimensional contrastenhanced magnetic resonance angiography (MRA) with digital subtraction angiography (DSA) which is the reference method in diagnosis of carotid artery stenosis and to compare the diagnostic efficiency of these two noninvasive methods.

Materials and Methods: The study encompassed 20 (15 males and 5 females) consecutive patients with a mean age of 55.85, who were admitted to Radiology Department with the symptoms of carotid artery stenosis. In each patient, 6 arterial segments were examined separately (left and right common, external and internal carotid arteries). While 6 arterial segments were examined separately (left and right common, external and internal carotid arteries). While RDUS was conducted in all patients, 18 patients underwent DSA, and 16 patients underwent MRA. In 14 patients, all
three methods were performed. According to stenosis levels, patients were divided into 5 groups which were $0-39 \%$, three methods were performed. According to stenosis levels, patients were divided into 5 groups which were $0-39 \%$, critical stenosis value of $70 \%$ ( $70 \%$ and above, and below $70 \%)$. DSA was considered as the gold standard method. McNemar, kappa, and Spearman's statistical tests were employed to calculate the sensitivity and specificity of CDUS and MRA, and correlation of those with DSA.

Results: In different stenosis levels, the sensitivity and specificity of RDUS were $100 \%$ and $95.3-99.1 \%$ where, the sensitivity and specificity of MRA were 100\% and 98.6-100\% ricity of RDUS were $100 \%$ and for RDUS were $100 \%$ and 99.1 and the sensitivy and specificity of MRA were $100 \%$ and $100 \%$ respectively. There was for RDUS were $100 \%$ and 99.1 and the sensitivy and specificity of MRA were $100 \%$ and $100 \%$ respectively. There was for MRA $r=1$ ). between DSA and other to methods. Repording the critical stenosis value of $70 \%$, the sensitivity of RDUS were $100 \%$ and 94,8 . Also there was a high correlation $(\kappa=0.80$ ) between RDUS and DSA, the sensitivity and spesifity of MRA were $100 \%$ and $\% 97.3$ respectively in diagrosing clinically significart stenosis ( $70 \%$ and above), and also kappa corelation with DSA was prerfeet $(\kappa=0.89)$.

Conclusion: The noninvasive methods of RDUS and MRA, with their high sensitivity and specificity values and lack of risks related to ionizing radiation and aterial catheterization, can be used effectively in detecting and grading the carotid artery stenosis as an alternative to DSA.

Key Words: Carotid Stenosis, Doppler Ultrasonography, MR Angiography, Catheter Angiography 
Ateroskleroza bağlı serebrovasküler patolojiler dünyada ölüm nedenleri arasinda ilk siralarda yer almaktadır. Akut inme olgularının yaklaşık \%20'si fatal olup \%55'i ise uzamış ya da geri dönüşü olmayan sekellerle karşı karşıya kalmaktadır $(1,2)$. Tedavi görmemiş transient iskemik atak (TİA) ya da persistan nörolojik defisiti olan inme olgular1 yeni bir serebrovasküler olay gelişimi açısından asemptomatik popülasyona göre 15-20 kat daha fazla risk taşımaktadır. Transient ya da kalıcı serebral iskeminin ancak $1 / 5$ 'inden kalp kaynaklı tromboemboliler sorumlu olup 4/5'i ise ateroskleroza bağlıdır (3). Kalıcı fonksiyon kaybına yol açan serebrovasküler iskemik olayların \%25'inin ekstrakranyal karotis arterlerde gelişmiş aterosklerotik plaklarin komplikasyonu olarak karşımıza çıkması, bu aterosklerotik lezyonların cerrahi tedavisini mümkün kılmaktadır (2,3). Tedavi seçenekleri arasında cerrahi (venöz veya sentetik greftin kullanılabildiği tromboendarterektomi) yani sira girişimsel radyolojik tedavi yöntemleri (perkütan translüminal anjiyoplasti (PTA) ve stent uygulaması) sayılabilir (3).

Hastaya en fazla yarar sağlayacak tedavinin planlanabilmesi için öncelikle patolojinin doğru bir şekilde ortaya konmas1 gerekmektedir. Karotis endarterektomi kararının verilmesinde en önemli faktörler hastanın klinik semptomatolojisi ve karotis arterdeki stenozun derecesidir. $\mathrm{Bu}$ nedenle stenoz derecesinin doğru bir şekilde ölçülmesi büyük önem taşımaktadır. İki geniş kapsamlı randomize çalışma olan "the North American Symptomatic Carotid Endarterectomy Trial" (NASCET) ve "the European Carotid Surgery Trial" (ECST) çalışmaları ile \%70'in üstünde ciddi stenozu olan olgularda karotis endarterektominin yarar sağladığı, inme ve ölüm riskini azalttığ1 kanıtlanmıștır (4-7). Kateter anjiyografi ya da dijital subtraksiyon anjiyografi (DSA), karotis arter stenoz ve oklüzyonlarının tanısında, "altın standart" yöntem olmakla birlikte invazif olması, rölatif olarak yüksek mortalite-morbiditesi (\%1-4) ve yüksek maliyeti nedeniyle tarama yöntemi olmaktan uzaktır. İnme ve TİA riskinin DSA sonras1 \%0.4-2 oranında olduğu bildirilmektedir (813). Hatta DSA'dan sonra belirgin bir nörolojik komplikasyonu olmayan hastalarda bile mikroembolilere bağl1 minör asemptomatik infarktlar geliştiği gösterilmiştir (14). DSA ile ilişkili bu problemler son yıllarda renkli Doppler ultrasonografi (RDUS) ve manyetik rezonans anjiyografi (MRA) gibi alternatif görüntüleme yöntemlerinin daha çok tercih edilmesine neden olmuştur. MRA ve RDUS noninvazif ve radyasyon içermeyen yöntemler olup teknolojik gelişmeler sayesinde tarama testi olarak kullanılabilir hale gelmiştir. $\mathrm{Bu}$ noninvazif teknikler gerek tek başlarına gerekse birbirlerini tamamlayıcı olarak kullanıldıklarında karotis arter stenozlarının tespitinde radyologa ve cerraha yararli bilgiler vermekte olup gereksiz anjiyografilerin büyük bir kısmını önleyebilmektedir. Ancak kateter anjiyografi, bilinen üstünlükleri dolayısı ile günümüzde halen referans inceleme yöntemi olmay1 sürdürmektedir. Ayrıca seçilmiş olgularda DSA kilavuzluğunda yapılan girișimsel radyolojik ișlemlerle (PTA ya da stent uygulaması gibi) cerrahiye gerek kalmaksızın tedavi sağlanabilmektedir.

$\mathrm{Bu}$ çalışmada semptomatik hastalarda RDUS ve kontrastlı 3 boyutlu MRA teknikleri ile elde edilen karotis arter stenoz oranlarının, DSA sonuçları ile karşılaştırılması ve bu iki noninvazif yöntemin tanısal etkinliği ve doğruluğunun araştırilması amaçlanmıștır.

\section{GEREÇ VE YÖNTEMLER}

Başağrıs1, TİA öyküsü, hemipleji, hemiparezi, hemihipoestezi, geçici görme kayb1, dengesizlik, vertigo tanımlayan ve klinik olarak karotis arter stenozu şüphesi ile başvurarak Ankara Üniversitesi Tip Fakültesi Radyoloji Anabilim Dalı'na refere edilen 20 ardiş1k olgunun DSA, RDUS ve 3 boyutlu MRA incelemeleri prospektif olarak incelendi. Her bir olguda sağ ve sol ana karotis arter (AKA), sağ ve sol internal karotis arter (İKA) ve sağ ve sol eksternal karotis arter (EKA) olmak üzere toplam 6 arter segmenti incelendi. Olguların tümü RDUS ile incelenirken 2 olguya böbrek fonksiyonlarının yüksek olması nedeniyle DSA, 4 olguya ise klastrofobi nedeniyle MRA yapilamadi. Dolayısıyla RDUS ile 120 karotis arter $(n=20$ olgu), DSA ile 108 karotis arter $(\mathrm{n}=18$ olgu) ve MRA ile 96 karotis arter ( $\mathrm{n}=16$ olgu) incelendi. On dört olguda (84 karotis arter) ise her üç görüntüleme metodu ile inceleme yapildı. İncelemelerin hepsi optimal kalitede olup değerlendirmeyi güçleștirebilecek teknik ya da hasta kaynaklı artefakt kaydedilmedi. Tüm olgular her bir tetkik öncesinde ayrıntılı olarak bilgilendirildi ve onamları alınd. Her üç inceleme sonuçları da, 3 ayrı radyolog tarafindan birbirinden bağımsız ve diğer incelemelerin sonuçlarından habersiz (kör) olarak değerlendirildi.

Sonografik inceleme Toshiba SSA 270A ve $380 \mathrm{~A}$, Power vision (Toshiba Cooperation, Tokyo, Japan) RDUS cihazlar1 ile $7.5 \mathrm{MHz}$ 'lik lineer prob kullanılarak yapildı. Cihaz filtre ve kazanç ayarları artefakt olușturmayacak ve en ayrıntılı bilgiyi elde edecek şekilde ayarland. Spektrum modunda hız ölçümlerinde Doppler açıları $30^{\circ}-60^{\circ}$ arasında olacak şekilde ayarlandı. İncelemeye sağda trunkus brakiyosefalikus, solda klavikula düzeyinden bașlanarak kranyale doğru sırayla AKA, ayrışım düzeyi, IKA ve EKA'lar incelendi.

Renk modunda damarda akımın lümeni doldurma paterni, plak saptanan bölgelerde jet veya türbülan akım varlığ1 ve darlık bölgesinde rezidüel lümen çapının o bölgedeki total damar çapına oranlanması ile stenoz dereceleri belirlendi. Spektral incelemede uygun Doppler açısı ayarlanarak stenotik alanda pik sistolik hız, diyastol sonu hız değerleri ölçüldü ve İKA/AKA pik sistolik ve 
diyastol sonu hiz oranları hesaplandi. Yapilan spektral stenoz değerlendirmeleri Moneta ve ark.'nın literatürde sunduğu değerlendirme parametrelerine göre düzenlendi (15).

Oklüzyon tanısı ise; gri skalada lümen ekojenisitesinde artış, renkli ve Power Doppler'de renk modu ve spektral incelemede akım saptanmamas1, tıkanıklığın proksimalindeki İKA bölümü ve AKA'da karşı tarafla kıyaslandığında yüksek dirençli, düşük hizlı hatta diyastolik komponenti negatif yönde akım örnekleri alınması esasina dayanarak konuldu.

MRA, 1.5 Tesla Signa Horizon görüntüleme sisteminde (GE Medical Systems, Milwaukee, Wisconsin, USA), "three-dimensional fast spoiled gradient recalled echo" (3D-
FSPGR) puls sekansı kullanılarak, arkus aortadan karotis sifonunaa kadar koronal planda elde edildi. Kontrast madde otomatik power enjektör (Medrad, Spectris) yardımı ile antekubital venden belirli hiz ve dozda verildi. Kullanilan parametreleri içeren görüntüleme protokolü Tablo 1'de sunulmaktadır.

Tablo 1: Kontrastlı karotis arter 3 boyutlu MRA incelemesinde kullanılan parametreler

\begin{tabular}{|ll|}
\hline Puls sekansı & 3D-FSPGR \\
Görüntüleme düzlemi & Koronal \\
Koil tipi & "NVARRAY" (nörovasküler array) \\
TR (time to repeat) (ms) & 4 \\
TE (time to echo) (ms) & $1.6-2$ \\
Flip angle (sapma açısı) & $30^{\circ}$ \\
FOV (cm) & $32 \times 19$ \\
Kesit kalınlığı (mm) & $2.4-3$ \\
Slab (görüntüleme) hacmi & Optimize \\
Matriks & $256 \times 128$ \\
Kesit sayısı & 76 \\
NEX (eksitasyon sayısı) & 0.75 \\
Süre (s) & $9-11$ \\
Kontrast miktarı (mL) & 20 \\
Enjeksiyon hızı (mL/s) & 2.5 \\
\hline
\end{tabular}

Bolus test uygulamasina gerek kalmadan sistem yazilıminda mevcut olan "smart prep" otomatik tetikleme fonksiyonu ile AKA ayrışım yeri düzeyinde intralüminal işaretleme yapilarak kontrast maddenin karotis arterlerde optimal düzeyde yakalanması sağlandi. İnceleme esnasinda hastalara nefes tutturulmadi. Toplam 40 saniye süren sekansta, 9-11 saniye içinde elde edilen ham görüntülerden multiplanar reformasyon ile maksimum intensite projeksiyon (MIP) görüntüler oluşturuldu. Değerlendirmeyi güçleştirecek derecede venöz dönüş kaydedilmedi.

Kateter anjiyografi tetkiki DSA ünitesinde (Multistar T.O.P. Siemens Medical Systems, Erlangen, Germany) gerçekleştirildi. Olgularda femoral arter yolu kullanilarak öncelikle arkus aortografi gerçekleştirildi. Sol anterior oblik ve sağ anterior oblik projeksiyonlarla supraaortik ana arterlerin çıkış düzeyleri değerlendirildi. Daha sonra Simmons serebral kateter (SIM 1, Torcon NB Advantage, Williamcook, EuropeA/S, Bjaeverskov) ile bilateral karotis arterler selektif olarak kateterize edilip saniyede 2 görüntü alarak, lateral ve oblik olmak üzere en az iki projeksiyonda imaj elde edildi. Incelemelerde non-iyonik iyotlu kontrast madde kiloya uygun dozda (maksimum doz $100 \mathrm{~mL}$ ) otomatik enjeksiyon cihazı ile verildi. Stenoz derecesi kateter ve MR anjiyogramlarda NASCET yöntemine göre, yani maksimum stenotik alandaki rezidüel lümen çapının bu düzeyin distalinde damar duvarlarının paralel duruma geldiği normal damar çapına oranı şeklinde hesapland1 $(4,5,16)$.
Saptanan patolojiler stenoz ve oklüzyon olarak 2 ana gruba ayrildı. Stenoz grubu da \%0-39, \%40-59, \%60-79 ve \%80-99 olmak üzere 4 alt gruba ayrılarak değerlendirildi. RDUS'de darlığa neden olmadığ saptanan plaklar, intimal kalınlaşmalar ile anjiyografide saptanan, darlığa neden olmayan duvar düzensizlikleri ve normal olarak değerlendirilen arterler \%0-39 grubuna dahil edildi. Diğer patolojiler her bir incelemede ayrı ayrı ölçülerek neden oldukları darlık derecesine göre sinıflandırıldı. Ayrıca NASCET'e göre kritik stenoz değeri olarak kabul edilen $\% 70$ ve üzeri darlıklar ile $\% 70$ altı darlıklara göre de ayrı bir sınıflandırma yapıldı (Şekil 1-4). 


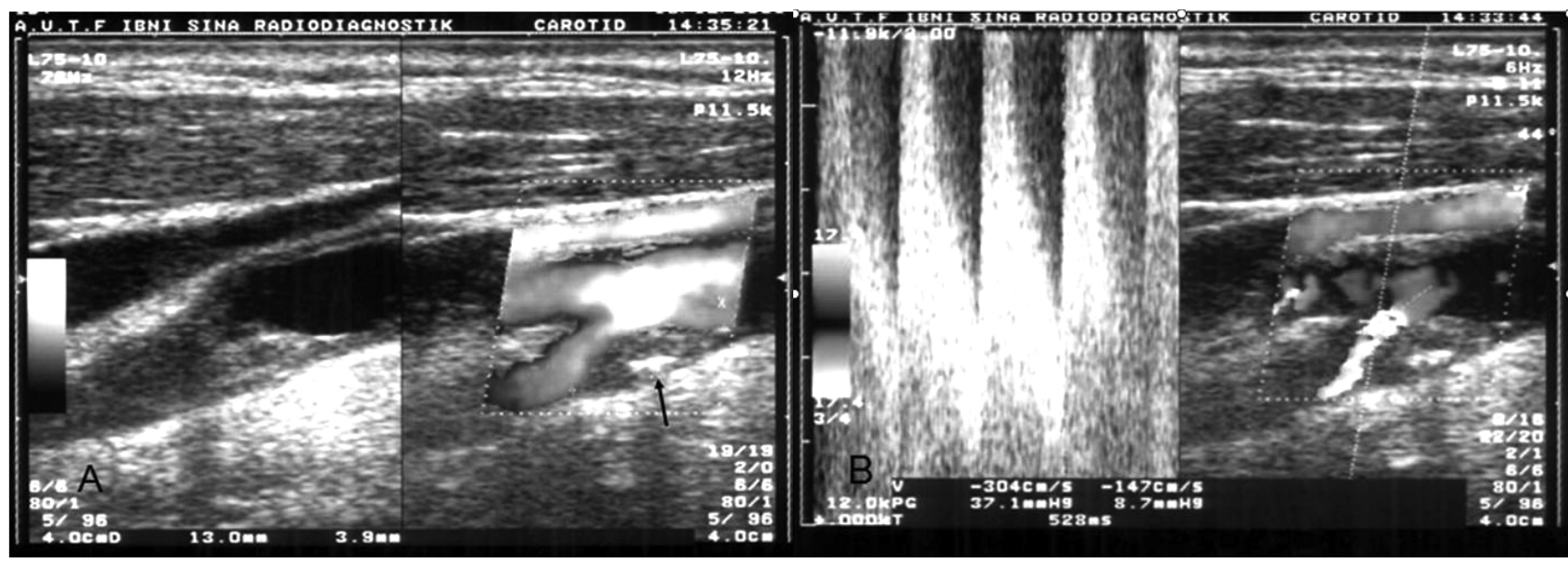

Şekil 1: Karotis bifurkasyon düzeyinde posterior duvarda, internal karotis artere uzanım gösteren, kısmen kalsifik aterom plağı (ok) izlenmektedir (A). Spektral analizde plağın internal karotis arterde \%80'in üzerinde lümen daralmasına yol açtığı (şiddetli stenoz) görülüyor (sistolik akım hızı $304 \mathrm{~cm} / \mathrm{sn}$, diastolik akım hızı $147 \mathrm{~cm} / \mathrm{sn}$ ).
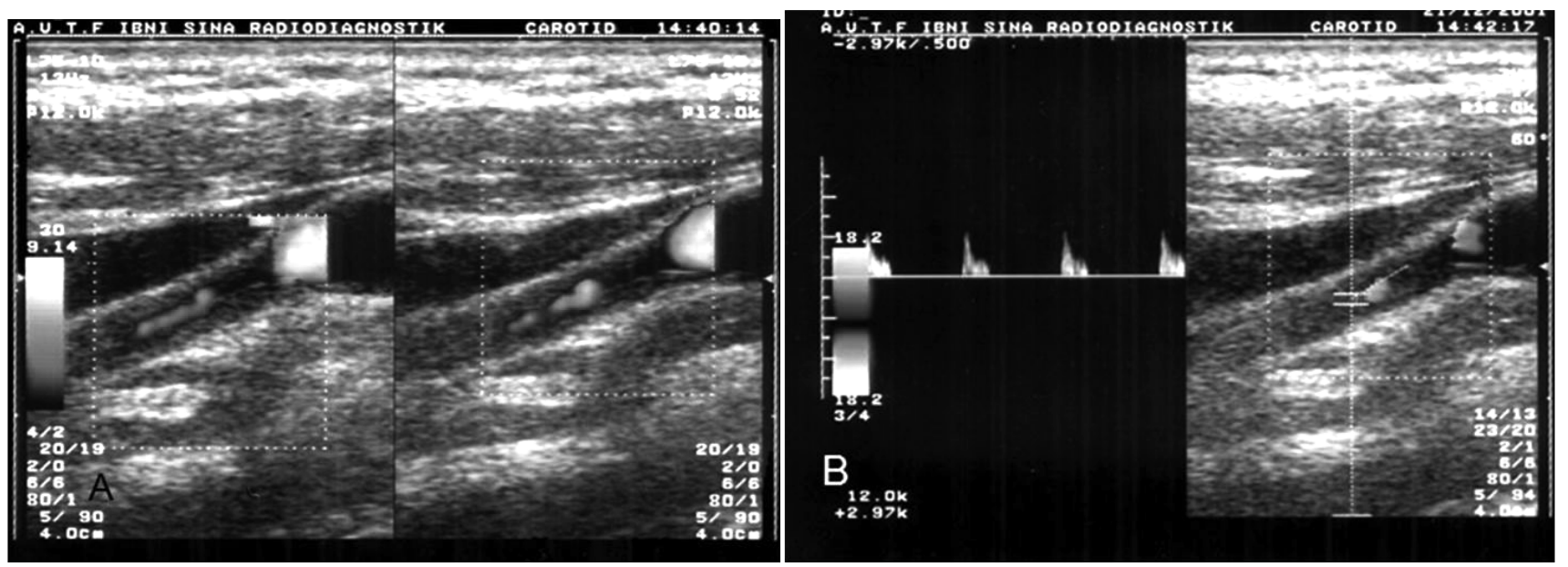

Şekil 2: İnternal karotis arterde power Doppler'de (A) arter lümeninde çok zayıf akım ve spektral analizde (B) ise oldukça düşük hızlarda, basıklaşmış akım deseni görülmektedir (preoklüziv stenoz).

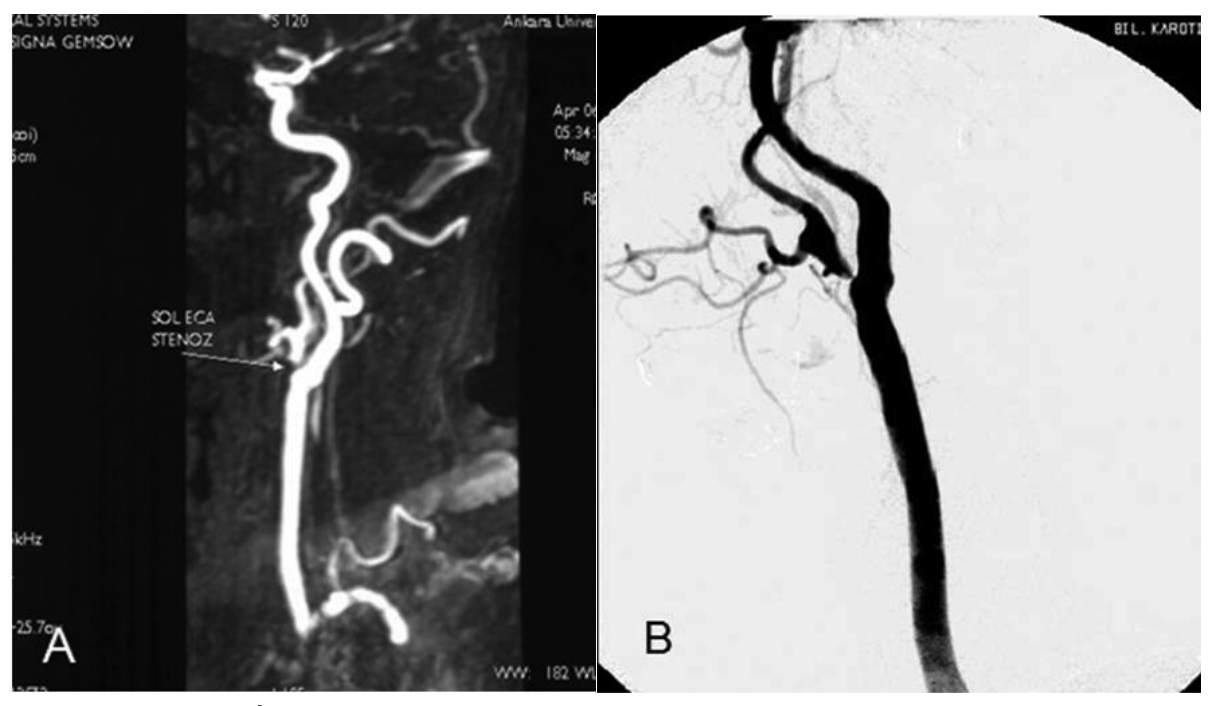

Şekil 3: Üç boyutlu MRA sagittal MiP görüntüsünde (A) ve aynı olguya ait kateter anjiyogramda (B) eksternal karotis arterde ileri derecede stenoz izlenmektedir. 


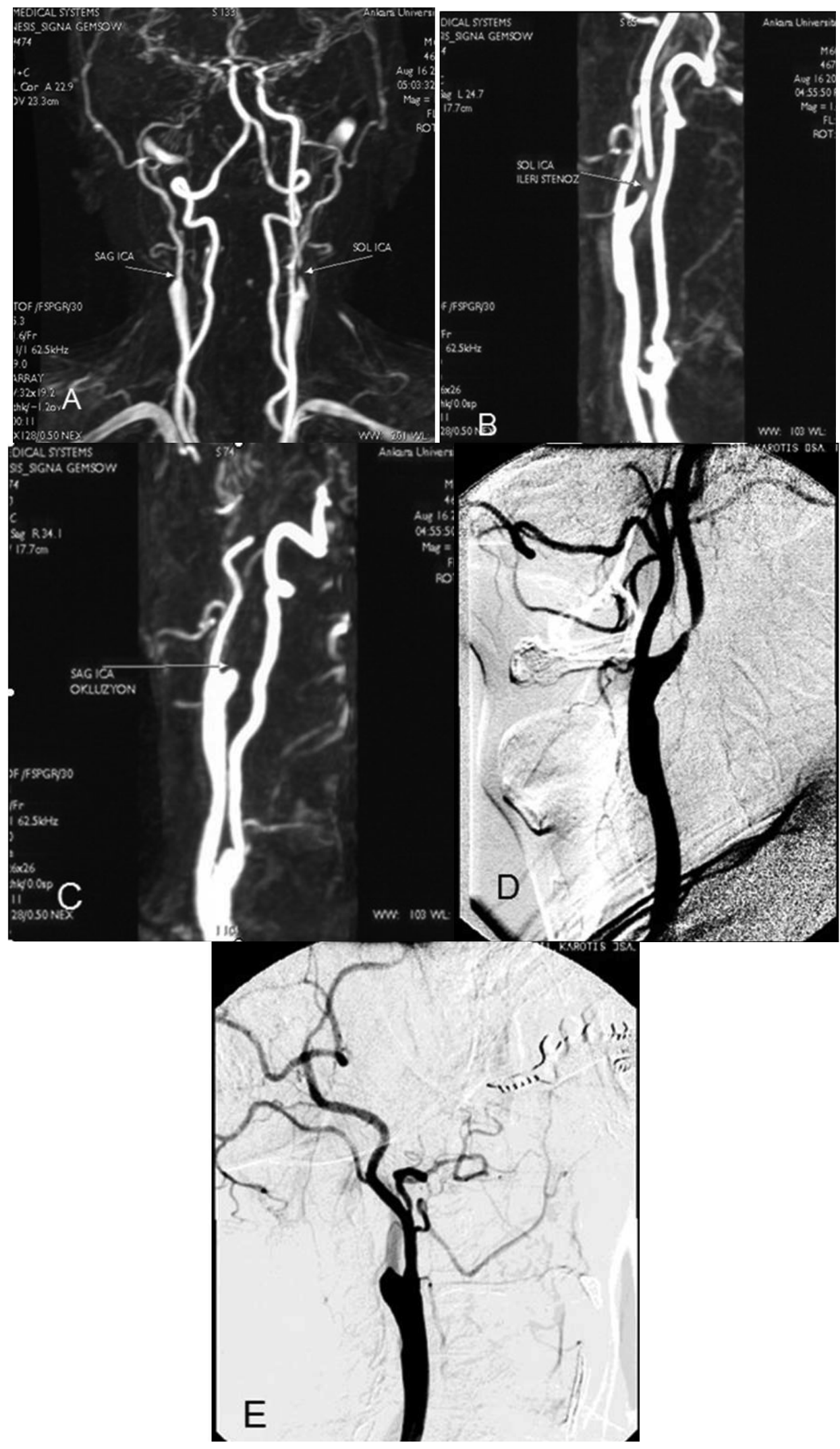

Şekil 4: Koronal $(A)$ ve sagittal $(B, C)$ MiP MR anjiyogramlarda sağ internal karotis arterin ayrışım düzeyinden kısa bir segment sonra tam olarak tıkandığı izlenmektedir. Ayrıca sol internal karotis arter proksimal kesiminde ileri derecede stenoza işaret eden sinyal kaybı mevcuttur. Aynı olguya ait DSA görüntülerinde $(D, E)$ MRA bulguları konfirme edilmektedir 


\section{İstatistiksel Analiz}

Çalışmamızda DSA incelemesi altın standart yöntem kabul edildi. Çeşitli stenoz derecelerindeki RDUS ve MRA sonuçları, referans yöntem DSA ile karşılaştırılarak her iki incelemenin karotis arter stenozunu saptamadaki duyarlılık, özgüllük ve uyumlar1 McNemar, kappa ve Spearman's korelasyon testleri ile belirlendi. Kappa analizi ile iki tanısal test arasindaki uyum derecesinin belirlenmesi amaçlandi. Kappa istatistiksel analizinde $0.81-1.00$ arasındaki katsayı değerleri mükemmel uyuma, 0.61-0.80 yüksek uyuma, 0.41-0.60 orta derecede uyuma ve 0.21-0.40 düşük uyuma işaret etmekte idi. Ayrıca kritik stenoz değeri olan \%70’e göre yapilan sinıflandırmaya göre de DSA ile RDUS ve MRA sonuçları karşıllaştırılarak duyarlılık ve özgüllükleri belirlendi.

\section{BULGULAR}

Çalışmaya toplam 20 olgu dahil edildi. Olguların 15'i erkek, 5'i kadın olup yaşları 33-80 arasında değişmekteydi (yaş ortalaması 55.85). Olguların hiçbirinde görüntüleme sırasında veya sonrasinda herhangi bir komplikasyon gelişmemiştir.

DSA ile incelenen 18 olgudaki 108 karotis arterin 86's1 (\%79.7) normal olarak değerlendirilirken, 22'si (\%20.3) patolojik bulundu. Patoloji saptanan arterlerin 16'sinda (\%72.7) stenoz, 6'sında (\%27.3) oklüzyon söz konusu idi. Stenozların 13'ü IKKA'da, 3'ü EKA'da belirlendi. AKA'da hemodinamik bozukluğa yol açan stenoz saptanmadi. Stenoz oranları göz önüne alındığında, patolojilerin 6's1 (\%27.2) \%40-59 grubunda, 5'i \%22.7) \%60-79 grubunda ve 5'i de (\%22.7) \% 80-99 grubunda belirlendi. Oklüzyonların hepsi İKA'da idi (5'i sağda, 1’i solda).

RDUS ile incelenen 120 arterin $(n=20$ olgu) 92'si (\%76.7) normal olarak değerlendirilirken, 28'inde (\%23.3) patoloji saptandi. Patolojik arterlerin 7'sinde (\%25) oklüzyon, 21'inde $(\% 75)$ stenoz belirlendi. Stenozlardan 3'ü AKA'da, 3'ü EKA'da, 15'i ise İKA'da idi. Stenoz oranları göz önüne alındığında, patolojilerin 6's1 (\%21.4) \%40-59 grubunda, 6's1 \%21.4) \%60-79 grubunda ve 9'u da (\%32.1) \%80-99 grubunda belirlendi.

MRA ile incelenen 16 olguya ait 96 arterin 76's1 (\%79.2) normal, 20'si $(\% 20.8) \quad$ patolojik olarak değerlendirildi. Stenozların 3 'ü EKA'da, 12'si ise İKA'da idi. Stenotik arterlerin 5'i (\%25) \%40-59 grubunda, 4’ü (\%20) \%60-79 grubunda, 6's1 (\%30) \%80-99 grubunda saptanırken, 5 'i ise $(\% 25)$ oklüzif olarak değerlendirildi.

Bu bulguların ıșığında, iki non-invazif metodun (RDUS ve MRA) saptadığ1 sonuçların DSA'ya göre dağılım ve uyumlulukları Tablo 2 ve 3'te, birbirleri ile dağılım ve uyumlulukları ise Tablo 4'te sunulmaktadir.

Tablo 2: Karotis arter patolojilerinin RDUS ve DSA'ya göre dağılım ve uyumlulukları

\begin{tabular}{|c|c|c|c|c|c|}
\hline \multirow{2}{*}{ RDUS'de saptanan stenoz dereceleri (\%) } & \multicolumn{5}{|c|}{ DSA'da saptanan stenoz dereceleri (\%) } \\
\hline & $0-39$ & $40-59$ & $60-79$ & $80-99$ & 100 \\
\hline $0-39$ & 82 & - & - & - & - \\
\hline $40-59$ & 4 & 2 & - & - & - \\
\hline $60-79$ & - & 3 & 3 & - & - \\
\hline $80-99$ & - & 1 & 2 & 4 & - \\
\hline 100 & - & - & - & 1 & 6 \\
\hline
\end{tabular}

Tablo 3: Karotis arter patolojilerinin MRA ve DSA'ya göre dağılım ve uyumlulukları

\begin{tabular}{|c|c|c|c|c|c|}
\hline \multirow{2}{*}{$\begin{array}{c}\text { MRA'da saptanan stenoz } \\
\text { dereceleri (\%) }\end{array}$} & \multicolumn{5}{|c|}{ DSA'da saptanan stenoz dereceleri (\%) } \\
\hline & $0-39$ & $40-59$ & $60-79$ & $80-99$ & 100 \\
\hline $0-39$ & 66 & - & - & - & - \\
\hline $40-59$ & - & 5 & - & - & - \\
\hline $60-79$ & - & 1 & 3 & - & - \\
\hline $80-99$ & - & - & - & 5 & - \\
\hline 100 & - & - & - & - & 4 \\
\hline
\end{tabular}

Tablo 4: Karotis arter patolojilerinin MRA ve RDUS'ye göre dağılım ve uyumlulukları

\begin{tabular}{c|ccccc}
\hline \multirow{2}{*}{ RDUS'de saptanan stenoz dereceleri (\%) } & \multicolumn{5}{|c}{ MRA'da saptanan stenoz dereceleri (\%) } \\
\cline { 2 - 6 } & $1-39$ & $40-59$ & $60-79$ & $80-99$ & - \\
\hline $1-39$ & 72 & - & - & - & - \\
$40-59$ & 4 & 2 & 2 & - & - \\
$60-79$ & - & 2 & 2 & 5 & 1 \\
$80-99$ & - & 1 & - & 1 & 4 \\
100 & - & - &
\end{tabular}


DSA ve RDUS ile incelenen 108 arterin 97'sinde (\%89.8) RDUS sonuçları DSA ile uyumlu bulunurken, 11'inde (\%10.2) farklı sonuç vermiştir.

DSA ve MRA ile incelenen 84 arterin 83'ünde (\%98.8) MRA sonuçları DSA ile uyumlu bulunurken 1'inde (\%1.2) farklı sonuç saptanmıştır.
Üç yöntemin de kullanıldığı 14 olguya (84 arter) ait sonuçlar birlikte değerlendirildiğinde, 84 arterin 73 'ünde (\%86.9) her 3 yöntemle aynı sonuçlar belirlenirken, 11'inde (\%13.1) farklı sonuca ulaşılmıştır. Buna göre; lezyonlar1 saptamada DSA ile RDUS \%89.8, DSA ile MRA $\% 98.8$, MRA ile RDUS \%88.5 uyumlu bulunmuştur.
Bu değerlerden yola çıkarak McNemar ve kappa testleri ile her bir stenoz derecesi için duyarlılık ve özgüllük hesaplandı. Buna göre RDUS için hesaplanan değerler Tablo 5'te, MRA için hesaplanan değerler ise Tablo 6'da verilmiştir.

Tablo 5: RDUS için hesaplanan duyarlılık, özgüllük, pozitif prediktif değer (PPD), negatif prediktif değer (NPD), $\kappa$ ve $p$ değerleri

\begin{tabular}{|c|c|c|c|c|c|c|}
\hline Stenoz Oranları (\%) & Duyarlılık (\%) & Özgüllük (\%) & PPD & NPD & $\kappa$ & $P$ \\
\hline $0-39$ & 100 & 95.3 & 84.6 & 100 & 0.89 & $<0.001$ \\
\hline $40-59$ & 100 & 95.7 & 80 & 100 & 0.87 & $<0.001$ \\
\hline $60-79$ & 100 & 96.9 & 78.6 & 100 & 0.86 & $<0.001$ \\
\hline $80-99$ & 100 & 99 & 85.7 & 100 & 0.92 & $<0.001$ \\
\hline Oklüzyon & 100 & 99.1 & 85.7 & 100 & 0.91 & $<0.001$ \\
\hline
\end{tabular}

Tablo 6: MRA için hesaplanan duyarlılık, özgüllük, pozitif prediktif değer (PPD), negatif prediktif değer (NPD), $\kappa$ ve $p$ değerleri

\begin{tabular}{|c|c|c|c|c|c|c|}
\hline Stenoz Oranları (\%) & Duyarlılık (\%) & Özgüllük (\%) & PPD & NPD & $\kappa$ & $P$ \\
\hline $0-39$ & 100 & 100 & 100 & 100 & 1 & $<0.001$ \\
\hline $40-59$ & 100 & 98.6 & 92.3 & 100 & 0.95 & $<0.001$ \\
\hline $60-79$ & 100 & 100 & 100 & 100 & 1 & $<0.001$ \\
\hline $80-99$ & 100 & 100 & 100 & 100 & 1 & $<0.001$ \\
\hline Oklüzyon & 100 & 100 & 100 & 100 & 1 & $<0.001$ \\
\hline
\end{tabular}

Farklı stenoz derecelerinde RDUS'nin ve MRA'nin duyarlılığının \%100; RDUS'nin özgüllüğünün \%95.3$\% 99.1$, MRA'nin özgüllügünün ise \%98.6-\%100 arasında değişmekte olduğu saptandi. Ayrica her bir stenoz ve oklüzyon grubunda RDUS ile DSA arasindaki uyum derecesi kappa istatistiksel analizi ile hesaplandığında mükemmel olarak belirlendi ( $\kappa=0.86-0.92)$. Aynı șekilde kappa istatistiksel analizi ile MRA ve DSA arasinda da mükemmel uyum saptand $1(\kappa=1)$.

Spearman's korelasyon testinde her bir inceleme için birbirleri ile karşılaştırıldıklarında kuvvetli pozitif korelasyon belirlendi ( $p<0.001)$. En güçlü korelasyon DSA ile MRA arasinda saptandi $(\mathrm{r}=1, \mathrm{p}<0.001)$.

NASCET'e göre kabul edilen kritik stenoz değeri olan $\% 70$ ' göre tüm sonuçlar $\% 70$ ve üzeri ile \%70'in altı olarak tekrar sinıflandırıldığında ise, $\% 70$ ve üzeri için RDUS'nin duyarlılığ1 \%100, özgüllüğü \%94.8 olarak bulundu. Ayrıca iki test arasinda yani RDUS ile DSA arasinda yüksek uyum saptand1 $(\kappa=0.80$, $\mathrm{p}<0.001)$. MRA'nin ise duyarlilı̆̆1 $\% 100$, özgüllüğü ise $\% 97.3$ olarak bulunurken DSA ile arasindaki uyum derecesi mükemmel olarak saptand $(\kappa=0.89, \mathrm{p}<0.001)$.

\section{TARTIȘMA}

Karotis endarterektomi öncesi preoperatif olarak karotis arter stenozlarının ve serebrovasküler dolaşımın değerlendirilmesinde DSA, halen "altın standart" görüntüleme yöntemi olma özelliğini korumaktadir. Ancak invazif bir yöntem olmasinın yanısıra, maliyetinin ve tecrübeli kişilerce yapılmadığ 1 takdirde komplikasyon oranının nispeten yüksek olması, noninvazif ve tarama testi olarak kullanılabilecek yeni görüntüleme yöntemlerine ihtiyaç duyulmasina neden olmuștur. Direkt ya da indirekt yöntemler olarak sinıflandırılabilecek bu yöntemler arasinda günümüzde en çok kullanılanları RDUS ve MRA'dır. RDUS ve MRA tekniklerinde son yillarda kaydedilen gelişmeler karotis arter patolojilerinin tanımlanmasinda söz konusu incelemelerin de önemli katkıs1 olabileceŏini göstermektedir. DSA artık günümüzde bir tarama yöntemi olmaktan çok, noninvazif görüntüleme yöntemleri ile incelenmiş olguların tedavi planlanmasinda ve/veya girişimsel tedavi işlemlerine rehberlik amaciyla kullanılmaktadır.

RDUS, ekstrakranyal karotis arter hastalığının değerlendirilmesinde semptomatik hastalarda ilk tanı testi, asemptomatik hastalarda ise tarama testi olarak kullanılan noninvazif bir 
görüntüleme yöntemidir (17-23). Birçok çalışmada, çeşitli Doppler kriterleri esas alınmasına rağmen, RDUS'nin doğruluk oranının \%90'ın üzerinde olduğu bildirilmektedir $(21,22)$. RDUS, aterosklerozun tüm aşamalarını, preklinik intimal-medial kalınlaşmadan total oklüzyona kadar çok başarılı ve doğru bir șekilde ortaya koymaktadır $(19,22,24)$. Alerji, böbrek yetmezliği gibi nedenlerle kontrast verilemeyen hastalarda güvenli bir şekilde kullanılabilir. Nispeten ucuz, tecrübeli kişilerce yapıldığında güvenilir, duyarlılığı ve özgüllüğü yüksek bir inceleme olup plak karakterizasyonu ve akim değişikliklerinin incelenmesinde anjiyografiye üstündür $(1,19,24)$. Çalışmalarda stenozun derecesi karotis endarterektomiye seçilecek hastaların belirlenmesinde tek bașına ayırtıcı bir faktör kabul edilmesine rağmen, artık plak morfolojisinin de bu açıdan önemli bir faktör olduğu ileri sürülmektedir (1,19). Hemodinamik olarak anlamlı stenoza yol açmasa da, heterojen plaklar emboliye ve akut trombozise yol açabilmektedir. Plak içi kanama, fissür ve ülserasyon, plağın rüptürüne yol açarak hastaların semptomatik hale gelmesine neden olmaktadır. Bu tip hastalarin da karotis endarterektomiden yarar sağlayabileceği öngörülmekte olup, plak karakterizasyonunu en iyi şekilde gösteren RDUS'nin de önemini arttırmaktadır (1,19). Ayrica aterosklerotik plak volümünün 3 boyutlu olarak gösterildiği US çalışmaları da mevcuttur $(25,26)$.

Tortüyoze damarlarda uygun açı verme sorunu, küçük ülserasyonların gözden kaçması ya da geniş ülserasyonların normal lümen gibi değerlendirilmesi nedeniyle stenoz derecesinin olduğundan düşük ölçülmesi, yüksek dereceli stenozların oklüzyon gibi değerlendirilmesi, kalsifik plağin oluşturduğu akustik gölgelenme, parametre seçimlerinde farkliliklar, operatöre bağımlılık, cihaza bağlı teknik farklar yöntemin sınırlamalarını oluşturmaktadır (1,17,18-24, 27-29). Çalışmamızda DSA'da kritik stenozu (\%80-99) olan
1 arter, RDUS'de akım saptanmamas1 nedeniyle oklüzyon olarak yorumlanmıştır (yanlış pozitif). Ayrıca 10 arter segmentinde ise RDUS'de saptanan stenoz oranları DSA'ya göre daha yüksek bulunmuştur. Buna göre farklı stenoz derecelerinde duyarlilik \%100, özgüllük ise \%95.3-99.1 olarak saptanmış olup istatistiksel olarak anlamlidır. Kappa analizinde ise RDUS ile DSA arasinda mükemmel uyum kaydedilmiştir $(\kappa=0.86-0.92)$. Yine RDUS'de oklüzyon ya da yüksek dereceli stenozun kontralateralindeki lezyonun olduğundan daha abartılı ölçülmesi olarak tanimlanan "overestimation fenomeni” de bilinmediği takdirde yanlış pozitif sonuçlara yol açabilecek bir sinirlamadir $(21,24)$. Bu fenomen, yüksek stenoz ya da oklüzyonun karş1 tarafinda, damar çap1 değişmeden kompansatuar akım artışının hız yükselmesine neden olması şeklinde açılanmaktadır (21). Çalışmamızdaki 6 oklüziv lezyonun 2'sinde kontralateral lezyon saptanmış olup biri kritik stenoz diğeri ise orta derecede stenoza işaret etmekteydi. $\mathrm{Bu}$ olgularda sonografik olarak İKA/AKA hiz oranlamasının kullanımı doğru ölçümü sağlamış olup sonuçlar DSA ile korele idi. Buradan çıkartılması gereken sonuç, RDUS incelemesi sirasinda, stenotik bir plak ile karşılaşıldığında pik sistolik hiz ve diyastol sonu hizın yanısıra, İKA/AKA oranının gözardı edilmemesidir. Çünkü bu oran akımı kisitlayan kritik stenozların belirlenmesinde yardımcıdır ve difüz olarak tüm karotis arterlerinde yüksek hız değerleri ölçülen hastalarda yanlışlıkla stenoz tanısının konulmasını önler (21).

Ülkemizde henüz kullanılmamakla birlikte literatürde karotis arter stenozlarında kontrastlı US ile ilgili çalışmalar mevcuttur. Kontrastlı US'nin vasküler çalışmalarda 2 önemli avantaj1 mevcuttur. Birincisi, AKA'nin adventisya tabakasında neovaskülarizasyon olup olmadığını saptayabilmesidir ki, bu bulgu erken dönem aterosklerozun bulgusu olan intima-media kalınlaşmasını göstermektedir. İkincisi, kontrastlı
US'nin, plak içi neovaskülarizasyonu tespit ederek plak morfolojisini kantifiye etmek için kullanılabilmesidir. Plak içi neovaskülarizasyonla kardiyovasküler patolojiler (miyokard infarktüsü, TİA, inme) arasinda direkt korelasyon mevcuttur $(24,30,31)$. Ciddi stenoz ve oklüzyonda kontrastlı US'nin, konvansiyonel US'ye göre daha başarılı olduğunu gösteren çalışmalar da mevcuttur (32,33). Bizim çalıșmamızdaki 6 oklüziv lezyonun tümü de US ile doğru olarak değerlendirilmiş, sadece bir hastada sonografik olarak oklüzyon olarak yorumlanan lezyon, DSA'da ileri stenoz olarak belirtilmiştir.

RDUS'nin teknik olarak ekstrakranyal damarlara sinırlı olması yöntemin başka bir dezavantajını oluşturmaktadır (17-19,28). Ateroskleroz yaygin bir hastalı olması nedeniyle birden çok damarı ya da bir damarda birçok bölgeyi tutabilmektedir. US'nin ise serebral sirkülasyonu, arkus aorta ve brakiyosefalik trunkusun proksimal kısminı direkt olarak değerlendirememesi nedeniyle tandem lezyonlar atlanabilmektedir ki, bu da tedavi seçimini değiştirebilecek bir etkendir (17). Worthy ve ark. yaptıkları bir çalışmada, ekstrakranyal karotis stenozu ile birlikte olgularının $\% 7$ 'sinde eșlik eden ciddi intrakranyal tandem lezyon saptamışlardır (17).

MRA, birçok vasküler sistemin görüntülenmesinde kullanılan noninvazif bir metod olup kateter anjiyografi gibi lüminal bir tekniktir. İki ve 3 boyutlu time-of-flight (TOF), faz kontrast (PC) tekniklerinin yerini son zamanlarda gradyent ve sekanslarda görülen gelişmeler, görüntülenen volüm içindeki kanın sinyal intensitesini arttırmak amacı ile gadolinyum kullanımı ve yüksek duyarlılık ve özgüllük oranları ile 3 boyutlu kontrastlı MRA almıştır. Üç boyutlu kontrastli MRA'nin PC ve TOF tekniklerine göre en önemli farkı akıma veya faz şifti etkisine bağımlı bir teknik olmamasıdır. Intravenöz olarak verilen gadolinyum kanın T1 relaksasyon zamanını 
k1saltarak, istenilen vasküler bölgeden ilk geçişi sırasında görüntü alınması esasına dayanır. Böylece yavaş akıma ve türbülansa bağlı sinyal kaybı yaşanmaz ve bu düzeydeki darlıklarda abartılı ölçüm engellenmiş olur $(32,34)$.

MRA'nin majör avantajlarından biri karotis bifurkasyo anatomisini DSA'ya benzer bir formatla göstermesidir, bu nedenle de cerrahlar tarafindan kabul görmektedir. Çünkü bifurkasyo ve stenoz bölgesinin yerinin operasyon öncesi kesin tayini gerekir. Ayrıca US'nin eksikliklerinden biri olan intrakranyal dolaşım ve arkus aorta demonstrasyonu sorunu MRA ile aşılmıştır (18). Yine kontrastlı MRA'nın üç boyutlu bir teknik olması, değişik açılardan birçok görüntü elde edilmesine ve maksimum çap daralmasının olduğu bölgenin kolaylıkla tanınmasına imkan verir, lümen açıklığı sayısal değerlerle ölçülebilir, hatta sanal anjiyoskopik görüntülerle intralüminal değerlendirme yapılabilir. İki boyutlu olan kateter anjiyografide ise selektif inceleme ve multipl projeksiyonlara rağmen ekzantrik stenozların atlanması sözkonusu olabilir (34-36).

Tüm MR anjiyografik metodlarda olduğu gibi, daha az derecelerde de olsa, kontrastlı MRA da, stenoz bölgesindeki türbülan akımin oluşturduğu faz kaybı ve parsiyel volüm etkileri nedeniyle stenoz oranını olduğundan daha yüksek ölçme eğilimindedir (37). Bu nedenle imaj analizleri, kaynak görüntüler ve MiP görüntüler birbiri ile korele edilerek yapilmalidir (37). Çalışmamızda, olguların MR anjiyogramlardaki lümen açıklığının kantitatif ölçümleri, ham görüntülerde aksiyel planda çap daralmasinin maksimum olduğu bölgenin ve alanınin tayini, daha sonra da bu sonucun normal damar çapının izlendiği distal İKA alanına oranı şeklinde yapılmıştır. Buna göre sadece bir arter segmentinde DSA'da hafif derecede (\%40-59) olan stenoz derecesi, MRA'da orta derecede stenoz $\quad(\% 60-79) \quad$ olarak değerlendirilmiştir. Diğer olgularda ise sonuçlar DSA sonuçları ile uyumlu bulunmuştur. Kappa uyum analizinde sadece \%40-59 stenoz derecesinde $\kappa=0.95$, diğer stenoz derecelerinde ise $\kappa=1$ olup MRA ve DSA arasinda mükemmel uyum mevcuttur.

İntravenöz paramagnetik kontrast ajanın görüntülenmesi istenen vasküler yapılarda arteriyel fazda yakalanması için enjeksiyon zamanlamasının doğru ayarlanması yüksek görüntü kalitesi için zorunludur (38). Ancak tüm optimal koşulların sağlanmasına karşın, yine de çalışmamızda olduğu gibi en s1k görülen artefakt zamanlama hatasına bağlı venöz dönüş olmasıdır. Özellikle dolaşımın hızlı olduğu genç hastalarda daha sık gördüğümüz bu artefakt, çalışmamızdaki olguların hiçbirinde yorumlamayı güçleştirecek düzeyde olmamıştır. Hafif düzeyde venöz opasifikasyon durumunda, ham ve reformat görüntüler birlikte değerlendirilmiştir. Yine 3 boyutlu MRA'larda sik görülen bir artefakt olan respiratuar artefakt, olgularımızda nefes tutturulmadığı için kooperasyon zorluğuna yol açmamış ve inceleme için bir sinırlama getirmemiştir.

BT anjiyografi (BTA) da karotis arter stenozunun saptanmasinda ve karakterizasyonunda yüksek duyarlilık ve özgüllüğe sahip bir inceleme yöntemidir. Multiplanar rekonstrüksiyon ile vasküler anatomi ve darlık yüzdesi çok iyi bir şekilde değerlendirilebilmektedir. Aterom plakları içindeki lipid, fibröz komponenti ve kalsiyumu ayırt edebilmektedir. Ayni seansta intrakranyal anatomi de ortaya konabilmekte ve böylece bu düzeyde eşlik eden patolojiler (darlık, anevrizma, vb) noninvazif olarak saptanabilmektedir. Ancak iyonizan radyasyon içermesi ve nefrotoksik kontrast madde kullanma zorunluluğu nedeniyle tedaviye cevabın takibi için uygun değildir $(1,24)$.

Son yıllarda pek çok çalışma grubu, RDUS ve MRA'nin tek başına veya birlikte uygulandıklarında alınan sonuçları DSA ile karşılaştırmış ve her birinin karotis stenoz tanısındaki duyarlilık ve özgüllügüünü araştırmıştır. Pan ve ark. in vivo olarak RDUS, DSA ve MRA ile elde ettikleri stenoz oranlarını, operasyon sonras1 ex vivo olarak MRG ile ölçülen plak stenoz oranı ile karşılaştırmışlar ve sonuç olarak, tüm modalitelerin ex vivo stenoz ile korele olduğunu ancak, RDUS'nin en iyi uyumu gösterdiğini bildirmişlerdir (35). Ayrıca aynı çalışmada anjiyografinin stenoz oranlarını olduğundan daha düşük ölçtüğü ileri sürülmüştür (35). Ancak arteryel basincın olmamasi nedeni ile ölçümlerin modifiye olması ve bulbusun $1 \mathrm{~cm}$ distalinden İKA ölçümlerinin yapılamaması nedeni ile bu yöntem referans olarak alınamaz (27,35). Yine postoperatif spesimenlerden yapilan histolojik stenoz ölçümleri ile DSA, MRA ve RDUS ölçümlerinin karşılaştırıldığ başka bir çalışmada da DSA'nın orta ve hafif dereceli stenoz oranların daha düşük gösterdiği, yüksek dereceli stenozlarda ise doğruluk oranlarının yüksek olduğu belirlenmiştir (39). Aynı çalışmada RDUS'nin ise özellikle yüksek dereceli stenozlarda oranları olduğundan daha yüksek ölçtüğü gösterilmiştir (39). Şahin ve ark'nın yaptı̆̆1 çalışmada, çeşitli stenoz derecelerinde duyarlilik oranları RDUS için \%80-100, spektral inceleme için \%77.7-100, özgüllük oranları RDUS için \%98.6-100, spektral inceleme için \%97.9-100 olarak bulunmuştur. Ayrıca stenoz derecesi arttıkça duyarlilık ve özgüllüğün arttı̆̆1, \%80-99 stenoz ve oklüzyonlarda ise bu oranlarin \%100'e ulaştığ1 saptanmıştır (40). Bizim bulgularımız da literatür sonuçları ile uyumludur. Polak ve ark'nın çalışmasında $\% 50$ ve üzerinde stenozlarda, RDUS duyarlllığ $\% 96$, özgüllüğü \%71; MRA duyarlılı̆̆1 \%96, özgüllüğü \%64 olarak bulunmuştur (28). Yine aynı yazarlar daha sonra yaptıkları bir çalışmada ise MRA ve RDUS'nin birbirlerini tamamlayıc1 incelemeler olduğunu, kendi çalışma olgularından karotis endarterektomi 
aday1 olanların \%79'unda anjiyografiye gerek kalmaksizın preoperatif değerlendirmenin yapıldığını belirtmişler ve anjiyografiye bu iki inceleme sonuçlarının uyumsuz olduğu, İKA'nın subtotal oklüzyonu veya tandem lezyonlardan şüphelenildiğinde başvurulabileceğini belirtmişlerdir (18). Bizim çalışmamızda da RDUS ve MRA ile değerlendirilen 96 arterin 10'u dışında sonuçlar birbirileri ile uyumlu bulunmuştur. Uyumsuzluğun olduğu 10 arterde RDUS'nin stenoz derecelerini MRA'ya göre daha yüksek ölçtüğü kaydedilmiştir. Buna göre her iki inceleme arasindaki korelasyon 0.80 olarak saptanmıștır (kuvvetli pozitif korelasyon). Ancak en güçlü korelasyon DSA ile MRA arasinda bulunmuştur $(r=1)$. DSA ile RDUS arasinda da kuvvetli korelasyon saptanmiştır $(\mathrm{r}=0.92)$. Serfaty ve ark'nın çalışmasında \%70 ve üzerindeki stenoz oranlarında 3 boyutlu MRA duyarliliğınin \%94, özgüllüğünün $\% 85$ olduğu, RDUS duyarlıllı̆ının \%64, özgüllüğünün $\% 97$, MRA ve RDUS kombine edildiğinde ise duyarlilik ve özgüllüğün \%100'e çıktığını ve gereksiz konvansiyonel anjiyografik incelemelerin \%61'ini önlediğini göstermişlerdir (27). Bizim çalışmamızda ise $\% 70$ ve üzeri stenozlarda gerek MRA gerekse RDUS'nin duyarlılık değerleri $\% 100$, özgüllük değerleri RDUS için \%94.8, MRA için \%97.3 bulunmuş olup RDUS ile DSA arasinda yüksek uyum $(x=0.80)$, MRA ile DSA arasinda ise mükemmel uyum $(x=0.89)$ saptanmıştır.

Kateter anjiyografinin hemodinamik değişiklikler hakkında bilgi vermemesi, damar duvarını net olarak değerlendirememesi, tecrübeli kişilerce yapılmadığı takdirde komplikasyon oranının nispeten yüksek olmas1, iyonize radyasyon ve nefrotoksik ajan kullanımı gibi dezavantajlar1 mevcuttur $(7,8,40,41)$. Ayrıca ölçüm yaparken distalindeki normal segment ile karșılaștırilan stenotik segmentin, bu bölgede de konsantrik yaygin plaklar olması durumunda darlık derecesi daha düşük ölçülebilir (40). Yine eksantrik plaklar lümenin oval görünümü ve radyogramların optimal X-1şını açısı ile alınamamasina neden olur ki, bu durumda açı lümen açıklığının sinırları ile teğet olamayacağı için stenoz oranı olduğundan düșük ölçülecektir (27,35). Ancak son yıllarda kateter tekniklerindeki gelișmeler, non-iyonizan düșük osmolariteli kontrast madde kullanımı, böbrek yetmezlikli olgularda kontrast maddenin dilüe edilerek kullanılması ya da gadolinyum gibi paramagnetik ajanlarin kontrast ajan olarak kullanımı yöntemin dezavantajlarını sinırlamaktadır (42).

Referans bir teknik olarak kateter anjiyografinin, RDUS ve MRA'ya göre üstünlükleri mevcuttur. Karotis endarterektomi öncesi mevcut anatomik varyasyonlarin ve bifurkasyonun tam lokalizasyonunu tespit etmek, kollateral varlığını ve yeterli olup olmadığını ortaya koymak cerrahi açıdan önemli olduğundan kateter anjiyografiye bașvurmak kaçınılmazdır. Ayrıca tedavi modalitesini değiştirebilen, aterosklerotik plakların sik yerleştiği bölgeler olan karotis sifonu ve arkus aortadan ayrışım düzeylerindeki tandem lezyonların tespitinde;
RDUS'de hemodinamik olarak belirgin stenoz saptanan ya da semptomlarla sonografik bulgularin korele olmadığı ya da incelemenin suboptimal olduğu durumlarda; RDUS ile MRA bulgularının korele olmadığ1 durumlarda; total oklüzyondan kuşkulanıliyorsa; fibromusküler displazi ya da spontan diseksiyon gibi az görülen vasküler patolojiler mevcutsa olgular anjiyografiye refere edilmelidir $(18,19,21,40)$.

Çalışmamızda DSA ile karşılaştırıldığında karotis arter stenozlarında MRA ve RDUS'nin tanısal değeri çok yüksek olarak bulunmuștur. Her iki noninvazif incelemenin birbirleri ile ve DSA ile karşılaştırılmaları sonucunda aralarında, MRA ile DSA arasında daha yüksek olmak üzere, kuvvetli pozitif korelasyon bulunmuștur. RDUS karotis arter stenozundan șüphelenilen olgularda ilk tanı testi ve asemptomatik olgularda tarama amaci ile kullanılabilecek, noninvazif, istenilen sıklıkla tekrar edilebilen, düşük maliyetli, komplikasyonu olmayan güvenilir bir tanı yöntemidir. Kontrastlı 3 boyutlu MRA, kateter anjiografiye benzer formatı ile cerraha ve girişimsel radyologa objektif, yol gösterici görüntüler sunmaktadır. Ayrıca nefrotoksik ajan kullanımını gerektiren kateter anjiyografiye de alternatif bir yöntemdir. Sonuc olarak, gerek RDUS gerekse kontrastlı 3 boyutlu MRA, çeşitli stenoz derecelerinde tespit edilen yüksek duyarlılık ve özgüllük değerleri ile, tek başlarına veya birlikte kullanıldıklarında karotis arter stenozu tanisinda güvenle kullanılabilecek tarama yöntemleridir. 


\section{KAYNAKLAR}

1- Anzidei M, Napoli A, Zaccagna F, et al. Diagnostic accuracy of colour Doppler ultrasonography, CT angiography and blood-pool-enhanced MR angiography in assessing carotid stenosis: a comparative study with DSA in 170 patients. Radiol Med 2012;117:54-71.

2- Rothwell PM, Coull AJ, Silver LE, et al. Population-based study of event-rate, incidence, case fatality, and mortality for all acute vascular events in all arterial territories. Lancet 2005;366:1773-1783.

3- Landewehr P. Carotid and vertebral arteries. In: Wolf KJ, Fobbe F, editors. Color Duplex Sonography: Principles and Clinical Applications. 1 ${ }^{\text {st }}$ ed. Germany: Georg Thieme Verlag; 1995; 45-66.

4- North American Symptomatic Carotid Endarterectomy Trial Collaborators. Beneficial effect of carotid endarterectomy in symptomatic patients with high-grade carotid stenosis. N Eng J Med 1991;325:445-453.

5- Barnett HJ, Taylor DW, Eliasziw M, et al. Benefit of carotid endarterectomy in patients with symptomatic moderate or severe stenosis: North American Symptomatic Carotid Endarterectomy Trial Collaborators. N Eng J Med 1998;339:1415-1425.

6- European Carotid Surgery Trialists' Collaborative Group. Randomised trial of endarterectomy for recently symptomatic carotid stenosis: final results of the MRC European Carotid Surgery Trial (ECST). Lancet 1998;351:1379-1387.

7- Rothwell PM, Eliasziw M, Fox AJ, et al, for the carotid endarterectomy trialists' collaboration. Analysis of pooled data from the randomised controlled trials of endarterectomy for symptomatic carotid stenosis. Lancet 2003;361:107-116.

8- Nederkoorn PJ, van der Graaf Y, Hunink M. Duplex ultrasound and magnetic resonance angiography compared with digital subtraction angiography in carotid artery stenosis: a systematic review. Stroke 2003;34:1324-1332.

9- Modaresi KB, Cox TCS, Summers PE, et al. Comparison of intra-arterial digital subtraction angiography, magnetic resonance angiography and duplex ultrasonography for measuring carotid artery stenosis. Br J Surg 1999;86:14221426.
10- Leffers AM, Wagner A. Neurologic complications of cerebral angiography. A retrospective study of complication rate and patient risk factors. Acta Radiologica 2000;41:204-210.

11- Davies KN, Humphrey PR. Complications of cerebral angiography in patients with symptomatic carotid territory ischaemia screened by carotid ultrasound. J Neurol Neurosurg Psychiatry 1993;56:967-972.

12- Johnston DC, Goldstein LB. Clinical carotid endarterectomy decision making: noninvasive vascular imaging versus angiography. Neurology 2001;56:10091015.

13- Heiserman JE, Dean BL, Hodak JA, et al. Neurologic complications of cerebral angiography. AJNR Am J Neuroradiol 1994;15:1401-1407.

14- Bendszus M, Koltzenburg M, Burger R, et al. Silent embolism in diagnostic cerebral angiography and neurointerventional procedures: a prospective study. Lancet 1999;354:15941597.

15- Moneta GL, Edwards JM, Chitwood RW, et al. Correlation of North American Symptomatic Carotid Endarterectomy Trial (NASCET) angiographic definition of $70 \%$ to $99 \%$ internal carotid artery stenosis with duplex scanning. J Vasc Surg 1993;17:152-159.

16- Osborn AG. Diagnostic Cerebral Angiography. $\quad 2^{\text {nd }}$ ed. Philadelphia: Lippincott Williams\&Wilkins; 1999; p. 370, p. 359-378, p. 421-440.

17- Worthy SA, Henderson J, Griffiths PD, et al. The role of duplex sonography and angiography in the investigation of carotid artery disease. Neuroradiology 1997;39:122-126.

18- Polak JF, Kalina P, Donaldson MC, et al. Carotid endarterectomy: Preoperative evaluation of candidates with combined Doppler sonography and MR angiography. Radiology 1993;186:333338 .

19- Khaw KT. Does carotid duplex imaging render angiography redundant before carotid endarterectomy? Br J Radiol 1997;70:235-238.
20- Urwin RW, Higashida RT, Halbach VV, et al. Endovascular therapy for the carotid artery. Neuroimag Clin North Am 1996;6:957-973.

21- Horrow MM, Stassi J, Shurman A, et al. The limitations of carotid sonography: Interpretive and technology-related errors. AJR Am J Roentgenol 2000;174:189-194.

22- Grant EG, Duerinckx AJ, El Saden SM, et al. Ability to use Duplex US to quantify internal carotid arterial stenoses: Fact or fiction? Radiology 2000;214:247-252.

23- Perkins JMT, Galland RB, Simmons MJ, et al. Carotid duplex imaging: variation and validation. Br J Surg 2000;87:320322 .

24- Byrnes KR, Ross CB. The current role of carotid duplex ultrasonography in the management of carotid atherosclerosis: foundations and advances. Int J Vasc Med 2012;2012:187872. doi: $10.1155 / 2012 / 187872$.

25- Landry A, Ainsworth C, Blake C, et al. Manual planimetric measurement of carotid plaque volume using threedimensional ultrasound imaging. Med Phys 2007;34:1496-1505.

26- Ludwig M, Zielinski T, Schremmer D, et al. Reproducibility of 3-dimensional ultrasound readings of volume of carotid atherosclerotic plaque. Cardiovasc Ultrasound 2008;6:42. doi: 10.1186/14767120-6-42.

27- Serfaty JM, Chirossel P, Chevallier JM, et al. Accuracy of three-dimensional gadolinium-enhanced MR angiography in the assessment of extracranial carotid artery disease. AJR Am J Roentgenol 2000;175:455-463.

28- Polak JF, Bajakian RL, O’Leary DH, et al. Detection of internal carotid artery stenosis: comparison of MR angiography, color doppler sonography, and arteriography. Radiology 1992;182:35-40.

29- Dix J, Skrocki J. Evaluation of carotid stenosis by angiography: potential bias toward overestimated measurements introduced by prior interpretation of doppler sonograms. AJNR Am J Neuroradiol 2000;21:639-642.

30- Feinstein SB. Contrast ultrasound imaging of the carotid artery vasa vasorum and atherosclerotic plaque neovascularization. J Am Coll Cardiol 2006;48:236-243. 
31- Cope C, Baum S. Catheters, methods, and injectors for superselective catheterization. In: Baum S, ed. Abram's Angiography. $4^{\text {th }}$ ed. Vol 1. USA: Little Brown and Company; 1997; 155-173.

32- Hammond CJ, McPherson SJ, Patel JV, et al. Asssessment of apparent internal carotid occlusion on ultrasound: prospective comparison of contrastenhanced ultrasound, magnetic resonance angiography and digital subtraction angiography. Eur J Endovasc Surg 2008;35:405-412.

33- Ohm C, Bendick PJ, Monash J, et al. Diagnosis of total internal carotid occlusions with duplex ultrasound and ultrasound contrast. Vasc Endovascular Surg 2005;39:237-243.

34- Prince MR. 3D Contrast MR Angiography. 2nd ed. Germany: Springer; 1999. p. 3-41, p. 151-162.

35- Pan XM, Saloner D, Reilly LM, et al. Assessment of carotid artery stenosis by ultrasonography, conventional angiography, and magnetic resonance angiography: Correlation with ex vivo measurement of plaque stenosis. J Vasc Surg 1995;21:82-89.

36- Hany TF, Schmidt M, Davis CP, et al. Diagnostic impact of four postprocessing techniques in evaluating contrastenhanced three-dimensional MR angiography. AJR Am J Roentgenol 1998;170:907-912.

37- Lee VS, Martin DJ, Krinsky GA, et al. Gadolinium-enhanced MR angiography: artifacts and pitfalls. AJR Am J Roentgenol 2000;175:197-205.

38- Hany TF, Debatin JF, Leung DA, et al. Evaluation of the aortoiliac and renal arteries: Comparison of breath-hold contrast-enhanced 3D MRA with conventional catheter angiography. Radiology 1997;204:357-362.

39- Netuka D, Ostry S, Belsan T, et al. Magnetic resonance angiography, digital subtraction angiography and Doppler ultrasonography in detection of carotid artery stenosis: a comparison with findings from histological specimens. Acta Neurochir 2010;152:1215-1221.

40- Șahin S, Tüney D, Gülsoy M, ve ark. Ekstrakranyal karotis-vertebral arter patolojilerinde renkli Doppler ultrasonografi ve anjiografi bulgularinin karşılaştırılması. Bilgisayarlı Tomografi Bülteni 1998;5:66-71.

41- Hankey GJ, Warlow CP, Molyneux AJ. Complications of cerebral angiography for patients with mild carotid territory ischaemia being considered for carotid endarterectomy. J Neurol Neurosurg Psychiatry 1990;53:542-548.

42- Matchett WJ, McFarland DR, Russell DK, et al. Azotemia: Gadopentetate dimeglumine as contrast agent at digital subtraction angiography. Radiology 1996;201:569-57 